\title{
Left ventricular blood flow kinetic energy is associated with the six-minute walk test and left ventricular remodelling post valvular intervention in aortic stenosis
}

\author{
Alaa Elhawaz ${ }^{1 \#} \wedge$, Gareth T. Archer ${ }^{1 \#}$, Hamza Zafar ${ }^{1}$, Benjamin Fidock ${ }^{1}$, Natasha Barker ${ }^{1}$, Rachel Jones ${ }^{1}$, \\ Alexander Rothman ${ }^{1}$, Rod Hose ${ }^{1}$, Abdallah Al-Mohammad ${ }^{1,2}$, Norman Briffa ${ }^{1,2}$, Steven Hunter ${ }^{2}$, \\ Peter Braidley $^{2}$, Ian R. Hall ${ }^{2}$, Ever Grech ${ }^{2}$, Rob J. van der Geest ${ }^{3}$, Julian P. Gunn ${ }^{1}$, Andrew J. Swift ${ }^{1}$, \\ James M. Wild ${ }^{1}$, Pankaj Garg ${ }^{1 \wedge}$ \\ ${ }^{1}$ Department of Infection, Immunity \& Cardiovascular Disease, University of Sheffield, Sheffield, UK; ${ }^{2}$ Sheffield Teaching Hospitals NHS \\ Foundation Trust, Sheffield, UK; ${ }^{3}$ Division of Image Processing, Leiden University Medical Centre, Leiden, The Netherlands
}

\#These authors contributed equally to this work.

Correspondence to: Dr. Pankaj Garg, MD (Hons), PhD. Clinical Lecturer in Cardiovascular Medicine, Department of Infection, Immunity \& Cardiovascular Disease, University of Sheffield, Medical School, Sheffield S10 2RX, UK. Email: pankaj.garg@nhs.net.

Background: Left ventricular (LV) kinetic energy (KE) assessment by four-dimensional flow cardiovascular magnetic resonance (4D flow CMR) may offer incremental value over routine assessment in aortic stenosis (AS). The main objective of this study is to investigate the LV KE in patients with AS before and after the valve intervention. In addition, this study aimed to investigate if $\mathrm{LV} \mathrm{KE}$ offers incremental value for its association to the six-minute walk test (6MWT) or LV remodelling post-intervention.

Methods: We recruited 18 patients with severe AS. All patients underwent transthoracic echocardiography for mean pressure gradient (mPG), CMR including 4D flow and 6MWT. Patients were invited for post-valve intervention follow-up CMR at 3 months and twelve patients returned for follow-up CMR. KE assessment of $\mathrm{LV}$ blood flow and the components (direct, delayed, retained and residual) were carried out for all cases. LV KE parameters were normalised to LV end-diastolic volume (LVEDV).

Results: For LV blood flow KE assessment, the metrics including time delay (TD) for peak E-wave from base to mid-ventricle $(14 \pm 48$ vs. $2.5 \pm 9.75 \mathrm{~ms}, \mathrm{P}=0.04)$, direct $(4.91 \pm 5.07$ vs. $1.86 \pm 1.72 \mu \mathrm{J}, \mathrm{P}=0.01)$ and delayed $(2.46 \pm 3.13$ vs. $1.38 \pm 1.15 \mu \mathrm{J}, \mathrm{P}=0.03)$ components of $\mathrm{LV}$ blood flow demonstrated a significant change between pre- and post-valve intervention. Only $\mathrm{LV} \mathrm{KE \textrm {i } _ { \mathrm { EDV } }}(\mathrm{r}=-0.53, \mathrm{P}<0.01)$, diastolic $\mathrm{KEi}_{\mathrm{EDV}}(\mathrm{r}=-0.53$, $\mathrm{P}<0.01)$ and $\mathrm{E}_{\text {wave }} \mathrm{KEi}_{\mathrm{EDV}}(\mathrm{r}=-0.38, \mathrm{P}=0.04)$ demonstrated association to the 6MWT. However, Pre-operative $\mathrm{LV} \mathrm{KEi} \mathrm{i}_{\mathrm{EDV}}(\mathrm{r}=0.67, \mathrm{P}=0.02)$ demonstrated association to $\mathrm{LV}$ remodelling post valve intervention.

Conclusions: LV blood flow $\mathrm{KE}$ is associated with $6 \mathrm{MWT}$ and LV remodelling in patients with AS. LV $\mathrm{KE}$ assessment provides incremental value over routine LV function and pressure gradient (PG) assessment in AS.

Keywords: Aortic valve stenosis; walk test; ventricular remodeling; exercise tolerance; echocardiography; Doppler; magnetic resonance imaging; 4D flow

Submitted Apr 19, 2020. Accepted for publication Oct 30, 2020.

doi: 10.21037/qims-20-586

View this article at: http://dx.doi.org/10.21037/qims-20-586

^ORCID: Alaa Elhawaz, 0000-0002-4228-7826; Pankaj Garg, 0000-0002-5483-169X. 


\section{Introduction}

Aortic stenosis (AS) is the third most common cardiovascular disease in Western countries and the commonest valvular disease requiring valve replacement $(1,2)$. Management of patients with AS depends on understanding the criteria for the assessment of the severity of the disease. According to the current European Society of Cardiology (ESC) or the European Association for Cardio-Thoracic Surgery (EACTS) guidelines, the indications for aortic valve replacement depend on the patient's symptoms and the severity of the stenosis (3). It is often debated which treatment option should be offered to yield optimum results. Therefore, appropriate diagnosis and classification of the disease severity are crucial for the management of AS. The haemodynamic effects of AS have significant implications on left ventricular (LV) remodelling (4). Although the main haemodynamic effect in AS is an increase in afterload due to the increased outflow resistance. However, preload is also affected as a consequence of $\mathrm{LV}$ compliance reduction (5). Thus, $\mathrm{LV}$ remodelling plays an important role in the clinical symptoms and leads to the development of heart failure in AS $(4,5)$.

Recent studies on novel biomarkers in AS have demonstrated the role of multi-parametric tissue characterisation by cardiovascular magnetic resonance (CMR) imaging (6-10). In the diastolic cascade, reduction in $\mathrm{LV}$ compliance results in raised $\mathrm{LV}$ filling pressure which in turn affects the trans-mitral or LV intra-cavity flow immediately (11). Subsequently, adverse myocardial remodelling will ensue. Hence, the assessment of LV blood flow using kinetic energy (KE) as a modality may offer a unique opportunity to detect early deterioration in AS.

$\mathrm{LV}$ intra-cavity blood flow $\mathrm{KE}$ (LV KE) assessment by four-dimensional flow (4D flow) CMR has been demonstrated to be superior to mitral inflow for its association to $\mathrm{LV}$ diastolic function (11). In addition, $\mathrm{LV}$ $\mathrm{KE}$ assessment can detect early changes in blood flow in myocardial infarct patients with preserved ejection fraction (12).

However, it remains unknown how the LV blood flow $\mathrm{KE}$ adapts to severe AS and also what happens to it after the reduction of afterload following valve intervention. The diagnostic value of this needs to be determined. Therefore, the main objectives of this study are: (I) to investigate the LV KE in patients with AS before and after the valve intervention, (II) to investigate if the KE of the blood flow components can provide an insight into the haemodynamic of AS, and finally, to study if $\mathrm{LV} \mathrm{KE}$ in patients with AS is associated with quantitative physical endurance evaluated by the six-minute walk test (6MWT).

\section{Methods}

\section{Study population}

This study was a sub-study of the EurValve project (http:// www.eurvalve.eu/). We prospectively recruited 18 patients diagnosed with severe AS by echocardiography. All patients with severe AS and in need of valve intervention at our centre between 2017 and 2018 were eligible for this study. Patients with significant disease of other valves or aortic regurgitation were excluded. We also excluded patients with coronary artery disease (CAD) requiring coronary artery bypass grafting surgery $(\mathrm{CABG})$, acute myocardial infarction or needing any coronary intervention, limited imaging data, any MRI contraindications or the inability to complete a $6 \mathrm{MWT}$.

\section{CMR examination}

All patients underwent CMR examination to acquire morphological images and 4D flow data. The 4D flow data were obtained during free-breathing, using an ECG-triggered, retrospectively navigator-gated, threedimensional, three-directional, time-resolved phasecontrast MRI sequence on a clinical 3T system (Ingenia, Philips Healthcare, Best, The Netherlands).

\section{CMR protocol and data acquisition}

The CMR protocol included complete short-axis cines covering the whole left ventricle for each acquisition, 3 sets of long-axis cines (two-, three-, and four-chamber), and 3-directional phase-contrast velocity images. Single heartbeat was divided into 20 time-steps to form the cine images. The number of slices varied according to the size of each patient's heart. Scan parameters for cines images included: SENSE with a speed-up factor of $2-3$, flip angle $45^{\circ}$, echo time (TE) $1.5 \mathrm{~ms}$, repetition time (TR) $3.05 \mathrm{~ms}$, spatial resolution of $2.5 \times 2.5 \mathrm{~mm}^{2}$, pixel size of $1.56 \times 1.56 \mathrm{~mm}^{2}$, field of view (FOV) $400 \mathrm{~mm}$, and a slice thickness of $6.0 \mathrm{~mm}$ with contiguous slices for the short axis stack.

\section{D flow acquisition}

Scan parameters for 4D flow acquisitions included: acquired 
spatial resolution of $3 \times 3 \times 3 \mathrm{~mm}^{3}$, TR $10.7 \mathrm{~ms}$, TE $3.5 \mathrm{~ms}$ and a reconstructed voxel size of $1.5 \times 1.5 \times 15 \mathrm{~mm}^{3}$. Other acquisition scan parameters of this sequence were: flip angle $10^{\circ}$, an approximate FOV of $340 \mathrm{~mm} \times 340 \mathrm{~mm}$, no slice gap, and $\mathrm{k}$-space segmentation factor of 3 . The number of signal averages was 1 , with 30 cardiac phases. Previously validated echo-planar acceleration (EPI) with a shot factor of 5 was applied (13). The velocity encoding (VENC) was obtained from echocardiographic images to reduce scan time and optimised if aliasing occurred, $150 \mathrm{~cm} / \mathrm{s}$ was used as a starting point and adjusted accordingly. These settings gave a temporal resolution of $40 \mathrm{~ms}$. After data acquisition, the $4 \mathrm{D}$ flow data was reconstructed into 30 -time frames on the scanner.

\section{D flow corrections}

Data pre-processing was done on the scanner for correcting phase offset errors such as eddy currents, Maxwell effects, and encoding errors related to gradient field distortions to avoid impairment of the measurements and inaccuracies in flow quantification $(14,15)$.

\section{Image analysis}

All images were post-processed and analysed using a previously validated method $(12,16)$. Manual contouring of the endocardial and epicardial surfaces, excluding the papillary muscles, was performed on the stack of short-axis cine images to obtain LV end-diastolic volume (LVEDV) and LV end-systolic volume (LVESV) in Mass software (Version 2019 EXP, Leiden University Medical Centre, Leiden, The Netherlands). From end-diastolic (ED) and end-systolic (ES) volumes, LV stroke volume (LVSV) and LV ejection fraction (LVEF) were calculated. Ventricular mass was calculated at end-diastole; the interventricular septum was considered part of the LV (17). During systolic phases, cautious segmentation of only those basal segments was done where there was evidence of myocardium and this was also confirmed in long-axis cines-both four-chamber and two-chamber cines.

The KE of each voxel of blood was computed using the following formula:

$\mathrm{KE}=1 / 2 \rho_{\text {blood }} \times \mathrm{V}_{\text {voxel }} \times \mathrm{v}_{\text {voxel }} 2$

Where the $\rho_{\text {blood }}$ represents the density of blood $\left(1.06 \mathrm{~g} / \mathrm{cm}^{3}\right)$, $\mathrm{V}$ voxel represents the voxel volume, and $\mathrm{v}$ represents the velocity magnitude. The total $\mathrm{LV} \mathrm{KE}$ was then computed in each time step as the summation of the $\mathrm{KE}$ of all voxels in the left ventricle and plotted by the software as a timeresolved KE curve where different KE parameters were derived from this curve. All KE parameters were normalized to $\mathrm{LV} \mathrm{EDV}$ and reported in $\mu \mathrm{J} / \mathrm{mL}$ (LV KEi $\mathrm{EDV}_{\text {EV }}$ (Figure 1).

\section{LV blood flow component analysis}

We applied a previously validated technique which enables the separation of the LV ED flow into four different functional components (18). LV short-axis cine stack, longaxis cine, and 4D flow images views were used for the analysis. The short-axis cine series was used to define the intraventricular blood particles. LV endocardial contours were manually traced in the ES and ED phases. The most basal short-axis slice in ES was used as inflow/outflow plane and particles were considered as invalid when they were either below the inflow/outflow plane or outside the LV epicardial contours in ES phase.

The ED blood flow was divided into four functional flow components, according to the transit of blood flow through the LV chamber for the complete cardiac cycle: (I) direct flow is the volume of the blood that enters the LV and ejected during the same cardiac cycle, (II) delayed ejection flow is the volume of the ejected blood that enters the left ventricle from a previous cardiac cycle, (III) retained inflow is the volume of the blood that enters the left ventricle but does not eject in the same cardiac cycle, and (IV) the residual volume is the blood that resides in the $L V$ over the entire cardiac cycle for at least 2 cardiac cycles. The results of particle tracing were reviewed visually and data quality was checked as previously described (18). After the quality was thoroughly assessed, the KE of the volume of each flow components were calculated over a complete cardiac cycle.

\section{$6 M W T$}

$6 \mathrm{MWT}$ was performed before and after the intervention according to the protocol based on the guidelines established by the American Thoracic Society (19).

\section{Statistical analysis}

Statistical analysis was carried out with IBM SPSS ${ }^{\circledR}$ Statistics (Version 25) software. All data were treated as non-parametric. Continuous measurements are presented as median with interquartile ranges (IQR). A paired nonparametric two-tailed test (Wilcoxon signed-rank test) was used for paired analysis. Mann-Whitney test was used 

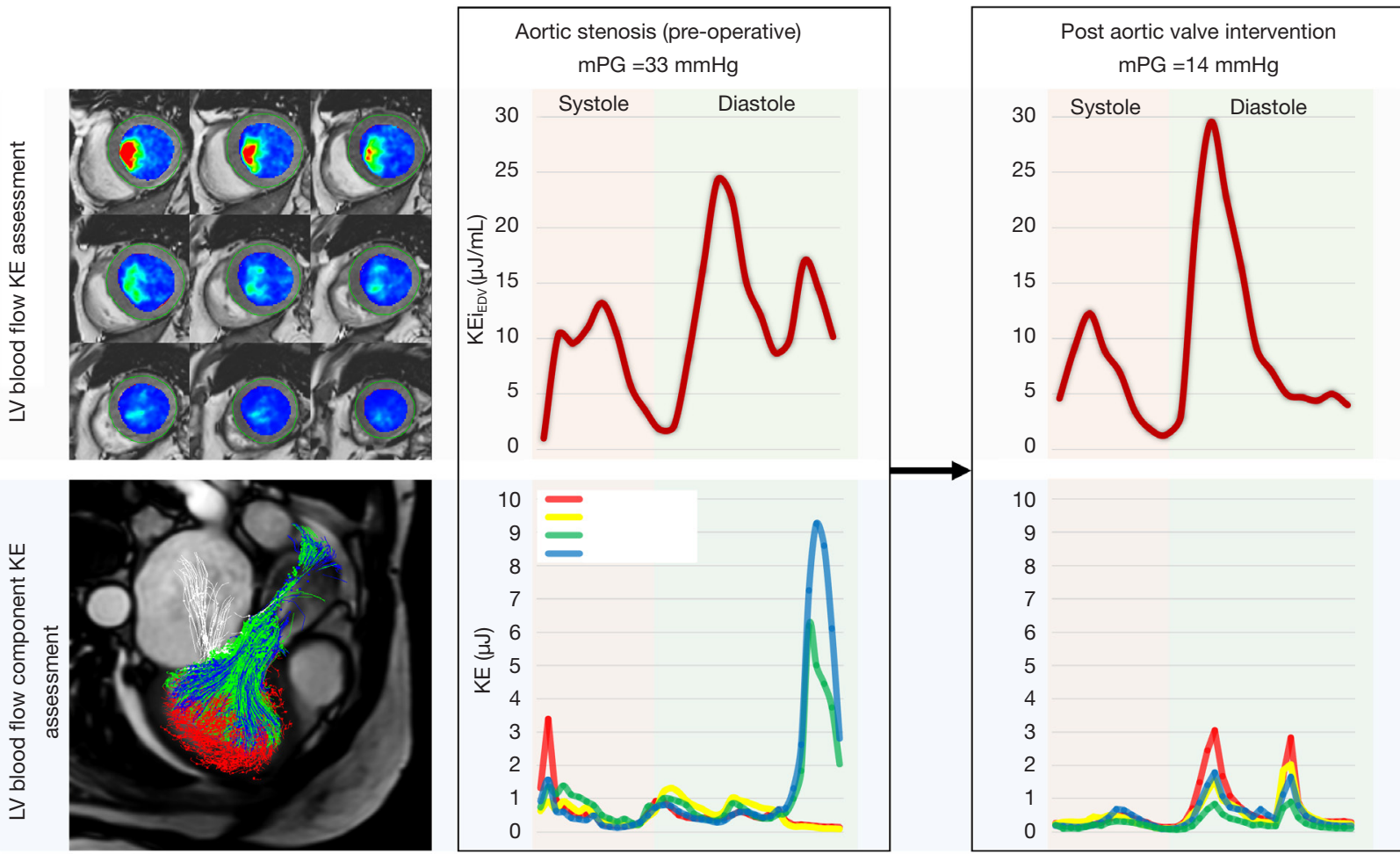

Figure 1 Case example from our study. The top panel demonstrates LV blood flow KE assessment. Even though the pattern was different for systolic and diastolic KE curves after intervention, the average quantified values for not significantly different. The second panel demonstrates a three-chamber image with superimposed particle tracing component analysis of the four LV blood flow components: retained inflow (yellow), residual volume (red), direct flow (green), and delayed ejection flow (blue). It is worth noting that the drop in direct and delayed flows was mainly observed in diastole. LV, left ventricle; KE, kinetic energy; mPG, mean pressure gradient.

for all continuous variables to compare differences between two different procedure options of the aortic valve. For investigating associations between two categorical variables, non-parametric Chi-squared test $\left(\chi^{2}\right)$ was used (20). Correlation between variables was assessed by Spearman correlation coefficient (rho), Value of $\mathrm{P}<0.05$ was considered significant. Results with a $\mathrm{P}$ value of $<0.05$ were considered statistically significant.

\section{Results}

\section{Demographic characteristics}

The demographic data of the patients were fully summarized in (Table 1). Eighteen patients completed the full study protocol with a mean age of 74.6, ranging from 53 to 89 years. Ten patients underwent SAVR whereas eight patients underwent TAVI procedure. SAVR patients were younger than TAVI patients $(68 \pm 8$ vs. $82 \pm 11$ years old,
$\mathrm{P}=0.01$ ), and the 6MWT was better in SAVR patients as compared to TAVI cohort $(409 \pm 182$ vs. $318 \pm 96.5$ meters, $\mathrm{P}=0.02)$. From 18 patients recruited, 6 were in atrial fibrillation (AF) (Table S1). Patients in AF had lower LVSV. On direct comparison, the heart rate (HR) was comparable in patients with $\mathrm{AF}$ versus in patients with sinus rhythm. Only one patient had a bicuspid aortic valve. A total of 6 post-operative patients including 1 SAVR and 5 TAVI declined to come back for research CMR scan. 4D flow CMR scans were performed between 2017 and 2018 at a mean time of 3 months before and after the intervention.

\section{Paired comparison of pre-and post-operative data changes}

\section{Haemodynamic parameters}

There were no significant changes in the systolic blood pressure and diastolic blood pressure or the HR after the valve intervention $(\mathrm{P}=0.41, \mathrm{P}=0.83, \mathrm{P}=1.0$ respectively). The transthoracic echocardiographic haemodynamic 
Table 1 Study demographics

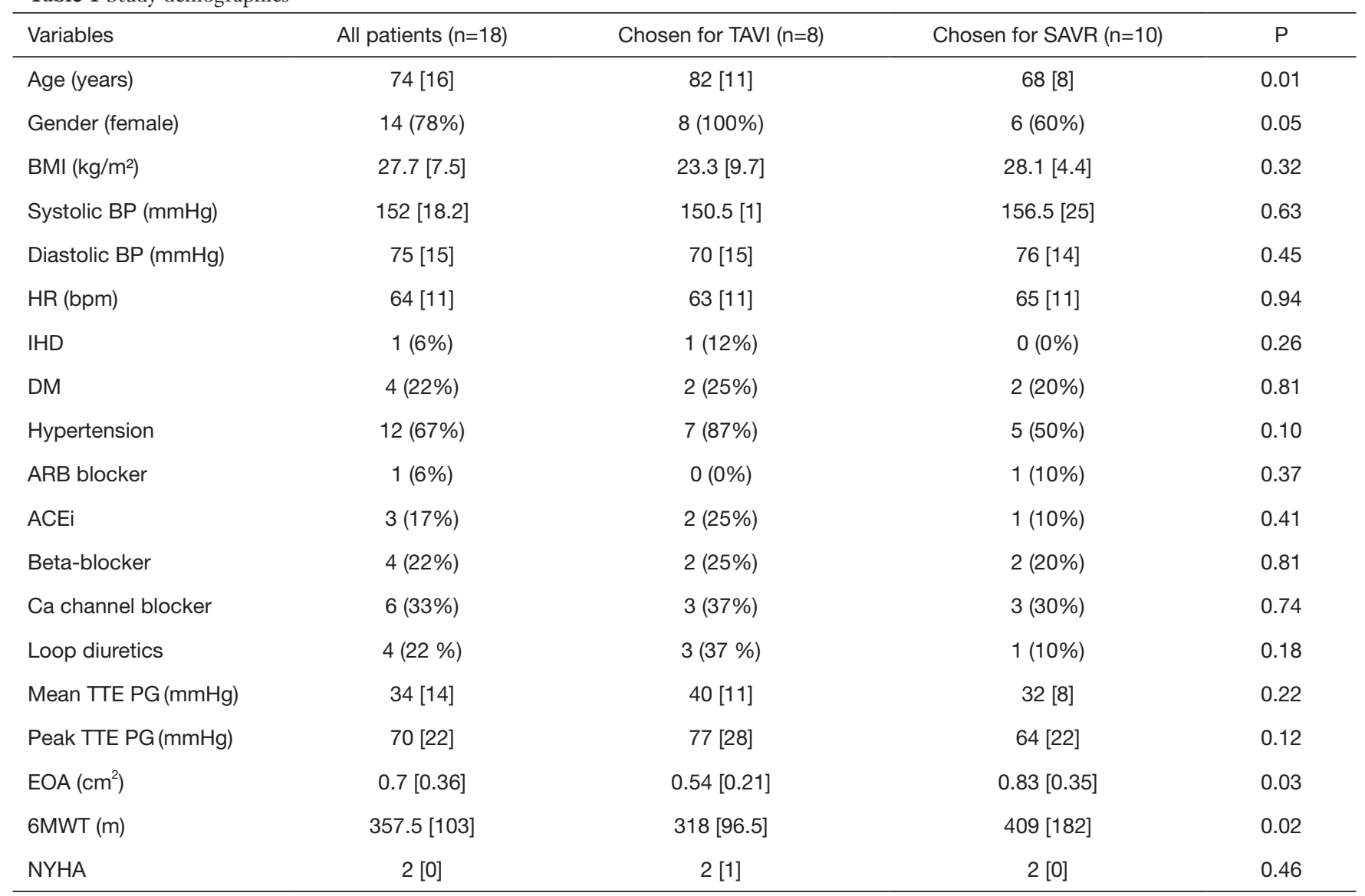

The data are shown as median [IQR], or $\mathrm{n}(\%)$. For all continuous variables, $\mathrm{P}$ value was done using the Mann-Whitney test. For all categorical variables, $\mathrm{P}$ value was calculated using the chi-squared test. ACEi, angiotensin-converting enzyme inhibitors; ARB, angiotensin II receptor blockers; BMI, body mass index; BP, blood pressure; Ca, calcium; DM, diabetes mellitus; HR, heart rate; IHD, ischemic heart disease; NYHA, New York Heart Association classification; PG, pressure gradient; TTE, transthoracic echocardiogram; 6MWT, 6-minute walk test.

measurement showed a significant reduction in the mean pressure gradient $(\mathrm{PG})(\mathrm{P}=0.001)$ (Figure 2). LVEDV, LV $\mathrm{SV}$, and LV mass were decreased significantly after the valve intervention $(\mathrm{P}=0.02, \mathrm{P}=0.009, \mathrm{P}=0.002$ respectively), however, there were no significant changes in both LVESV and $\mathrm{EF}(\mathrm{P}=0.09, \mathrm{P}=0.38$ respectively) (Table 2).

\section{KE parameters}

Table 2 provides a full summary of $\mathrm{LV} \mathrm{KE \textrm {K } _ { \mathrm { EDV } }}$ parameters before and after the intervention. The results from Wilcoxon analysis demonstrated that pre and post aortic valve interventions (SAVR/TAVI), average $\mathrm{LV} \mathrm{KEi_{ \text {EDV } }}$ $(12.0 \pm 3.4$ vs. $11.2 \pm 4.6 \mu \mathrm{J} / \mathrm{mL})$, average systolic $\mathrm{LV} \mathrm{KE \textrm {i } _ { \mathrm { EDV } }}$ $(10.3 \pm 3.8$ vs. $11.8 \pm 5.0 \mu \mathrm{J} / \mathrm{mL})$, and average diastolic $\mathrm{LV}$ $\mathrm{KEi}_{\mathrm{EDV}}(12.5 \pm 2.9$ vs. $11.8 \pm 6.3 \mu \mathrm{J} / \mathrm{mL})$, were comparable
$(\mathrm{P}=0.52, \mathrm{P}=0.85, \mathrm{P}=0.27$ respectively). Furthermore, there were no significant changes in the early and late diastolic (E and $\mathrm{A}$ waves) peaks ( $\mathrm{P}=0.38, \mathrm{P}=0.91$ respectively).

The relative drop in mitral flow KE parameters (from base to mid-ventricle and from mid-ventricle to apex) were also not changed significantly after the valve intervention $(\mathrm{P}=0.27, \mathrm{P}=0.15)$.

\section{Early diastolic time delay (TD)}

Figure 2 shows the change of TD and some CMR functional parameters before and after the intervention for all the patients. The delayed time for the travel of the blood from the base to mid-ventricle during the early diastolic phase (TD) was significantly decreased after the valve procedure (14 \pm 48 vs. $2.5 \pm 9.75$ msec, $\mathrm{P}=0.04$ ) (Table 2). 

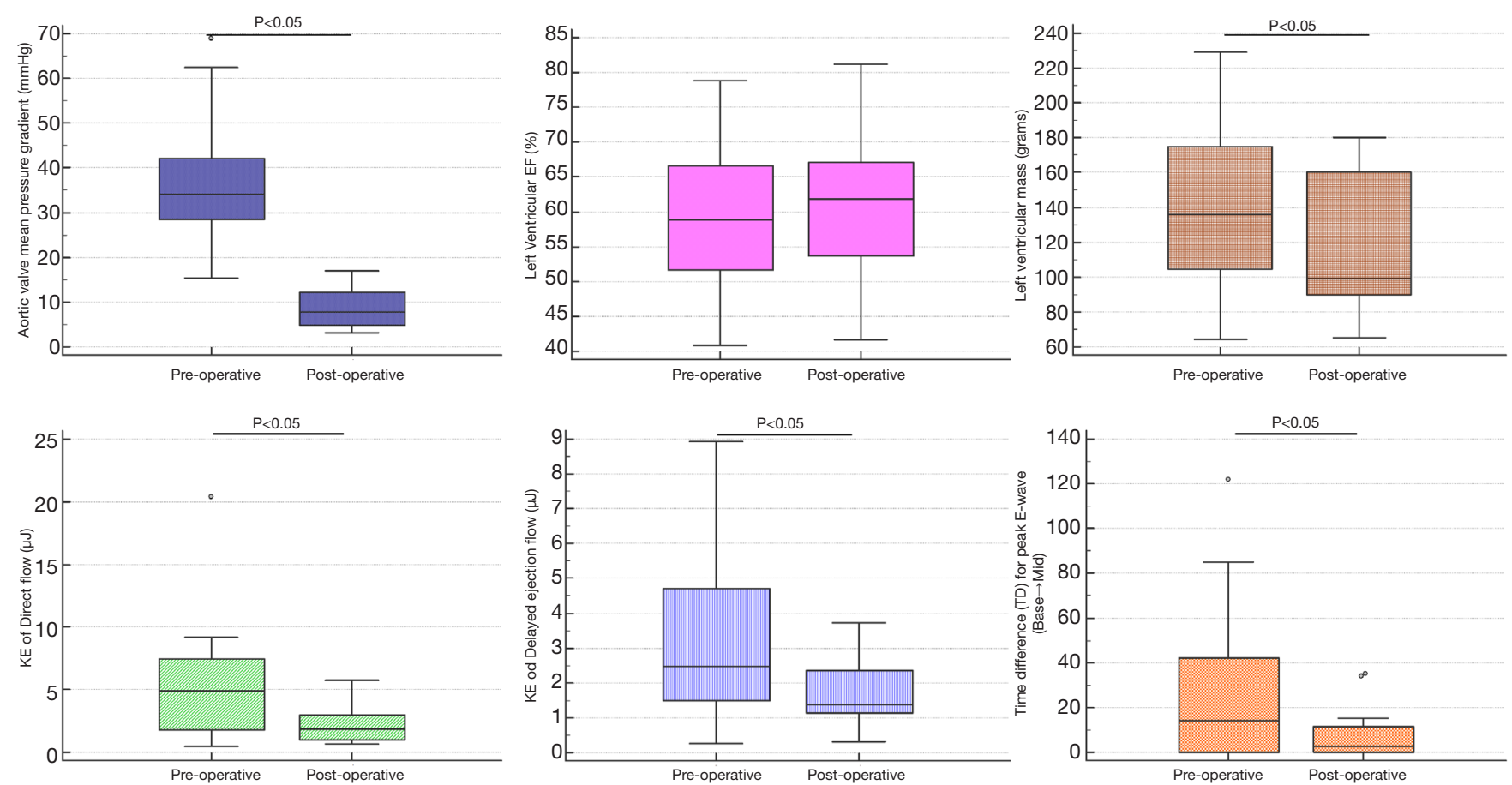

Figure 2 Pre and post aortic valve intervention box and whisker charts demonstrating a significant drop in LV mass and the associated drop in TD (msec), direct and delay LV blood flows. LV, left ventricle; TD, time delay.

\section{Flow components analysis}

The volume and distribution of the $\mathrm{LV}$ flow components were determined in all patients before and after the intervention. The calculated volumes of LV inflow and outflow were well matched (concordance correlation coefficient $=0.91,95 \%$ confidence interval, 0.83 to 0.96 , $\mathrm{P}<0.0001$; mean bias $=-0.82,95 \%$ confidence interval -3.5 to $1.9, \mathrm{P}=0.55 ; 41.76 \pm 17.69$ vs. $42.11 \pm 18.07 \mathrm{~mL}, \mathrm{P}=0.59$ ). The Wilcoxon analysis of the blood component KE reveals that the $\mathrm{KE}$ of both direct flow and delayed flow was significantly reduced after the intervention $(\mathrm{P}=0.01, \mathrm{P}=0.04$ respectively) (Table 2), whereas no significant changes were noted for the LV KE of the other two components (Table 2).

\section{Association with 6MWT}

There were no significant differences in the preoperative versus postoperative $6 \mathrm{MWT}(373 \pm 96.6 v s .360 \pm 146$ meters, $\mathrm{P}=0.76$ ). The results from the non-parametric Spearman's analysis revealed that there was a significant negative correlation between $6 \mathrm{MWT}$ and the average $\mathrm{LV} \mathrm{KE \textrm {E } _ { \mathrm { EDV } }}$ $(\mathrm{r}=-0.53, \mathrm{P}=0.003)$, average diastolic $\mathrm{KEi}_{\mathrm{EDV}}(\mathrm{r}=-0.53$, $\mathrm{P}=0.003)$, and peak $\mathrm{E}$-wave $\mathrm{KEi}_{\mathrm{EDV}}(\mathrm{r}=-0.38, \mathrm{P}=0.04)$ (Figure 3). 6MWT correlated positively with the relative drop in mitral flow $\mathrm{KEi}_{\mathrm{EDV}}(\mathrm{r}=0.40, \mathrm{P}=0.033)$. However, there was no correlation observed with the other $\mathrm{LV} \mathrm{KEi_{ \textrm {EDV } }}$ parameters. Interestingly, $6 \mathrm{MWT}$ did not correlate with $\mathrm{KE}$ of the four blood components (Table 3) respectively.

There was positive correlation between 6MWT and both LVEDV, SV ( $r=0.36, \mathrm{P}=0.05 ; \mathrm{r}=0.36, \mathrm{P}=0.05$ respectively), however, LVESV, LV mass, and EF did not show any significant correlation with $6 \mathrm{MWT}(\mathrm{P}=0.18, \mathrm{P}=0.49, \mathrm{P}=0.22$ respectively) (Table 3).

\section{Association with NYHA classification}

There was no significant association between the imaging parameters and the patient's symptoms assessed by NYHA classification (Table 3).

\section{Association with $\mathrm{LV}$ remodelling}

From the LV KE parameters, only the preoperative average $\mathrm{KEi}_{\mathrm{EDV}}$ was significantly correlated with the absolute change in $\mathrm{LV}$ mass post-operatively $(\mathrm{P}=0.02)$ (Table 4 and Table S2). Preoperative routine assessment (LV EF and mean TTE PG) did not show any significant changes with $\mathrm{LV}$ remodelling in the post-operative phase $(\mathrm{P}=0.25, \mathrm{P}=0.73$ respectively) (Figure 4). 
Table 2 Paired comparison of pre- and post-operative changes in cardiac haemodynamics, imaging parameters and functional parameters at 3 months ( $\mathrm{n}=12)$

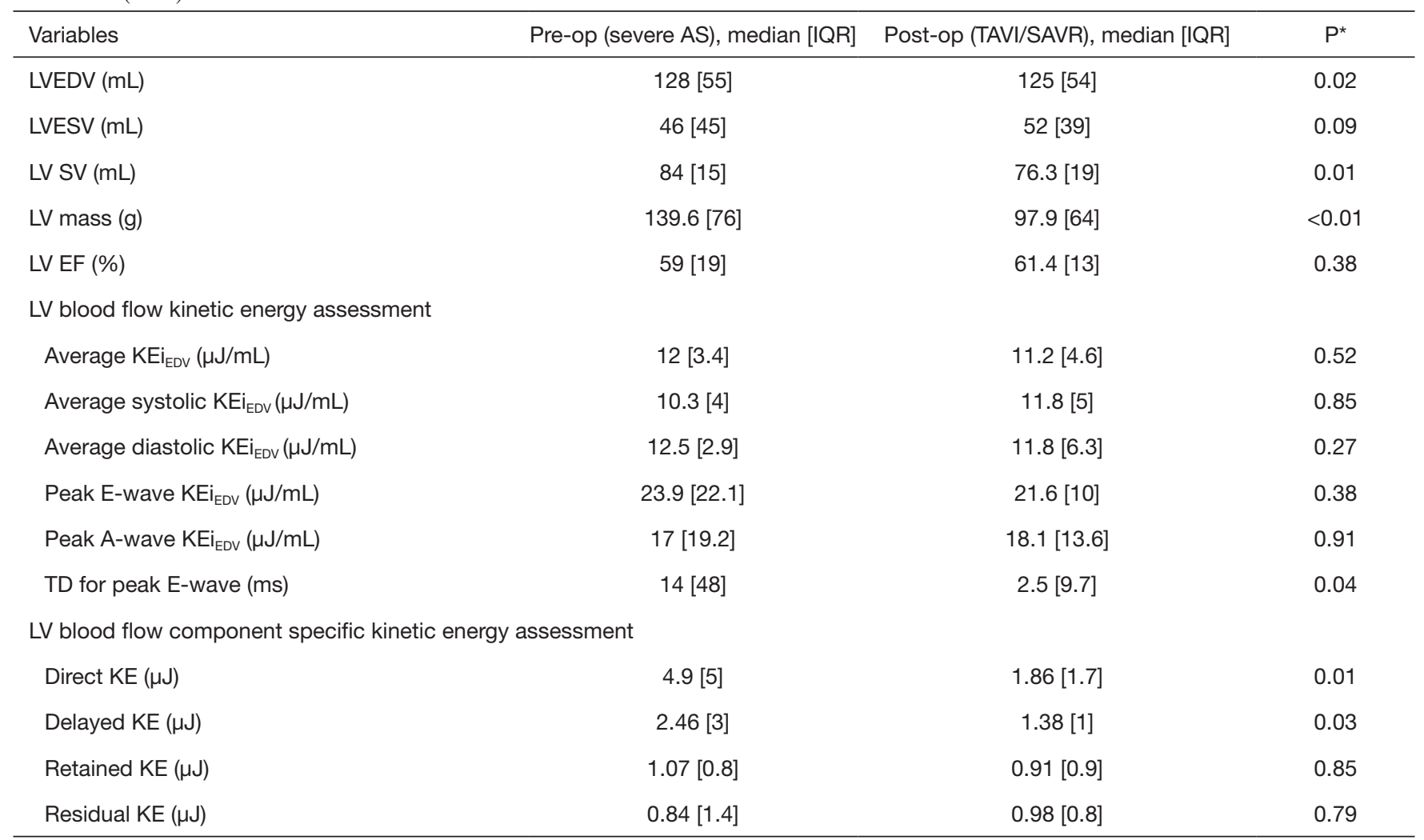

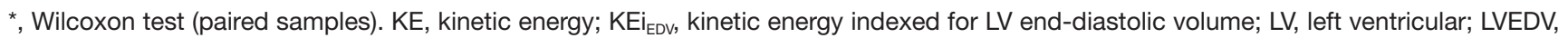
left ventricular end-diastolic volume; LVESV, left ventricular end-systolic volume; SV, stroke volume; EF, ejection fraction; TD, time delay.

\section{Discussion}

To our knowledge, this is the first study to report the LV blood flow $\mathrm{KE}$ in patients with AS-both in pre and post valvular intervention stages. In addition, this study gives mechanistic insight into changes associated with AS in the assessment of KE of the blood flow component. The main findings of this study include that the average $\mathrm{KE}$ of the blood flow through the left ventricle does not change significantly following valve intervention. However, the $\mathrm{TD}$, direct flow and delayed flow are significantly altered post valvular intervention. In addition, LV blood flow KE metrics demonstrated best association with the 6MWT. Finally, LV remodelling at 3-months was only associated with the delayed flow component of $\mathrm{LV}$ flow.

\section{LVKE before and after the intervention}

The results from our study reveal that the LV blood flow $\mathrm{KE}$ does not change significantly after valve intervention and thus remains preserved. This was an unexpected finding-however, we speculate that this is the result of energy preservation of blood flow coupled with left ventricle mechanics. However, different components of blood flow $\mathrm{KE}$ demonstrated changes in pre valve intervention to post valve intervention cohort. Both direct and delayed flow components $\mathrm{KE}$ were significantly reduced post valvular intervention. It is worth noting that the rise in direct and delayed flow components in severe AS patients was mainly observed in late diastolic filling phase (Figure 1). However, further research is warranted to explain this phenomenon.

In our study, LV blood flow KE demonstrated inverse correlation to the quantitative physical endurance, i.e., the 6MWT. This was not seen for standard CMR derived functional and volumetric assessment. Several studies have reported that the $6 \mathrm{MWT}$ is a reliable measure of the overall impact of a clinical condition and a predictor of increased mortality (21-23). Hence, an increase in the LV blood flow KE may provide a novel haemodynamic biomarker of 


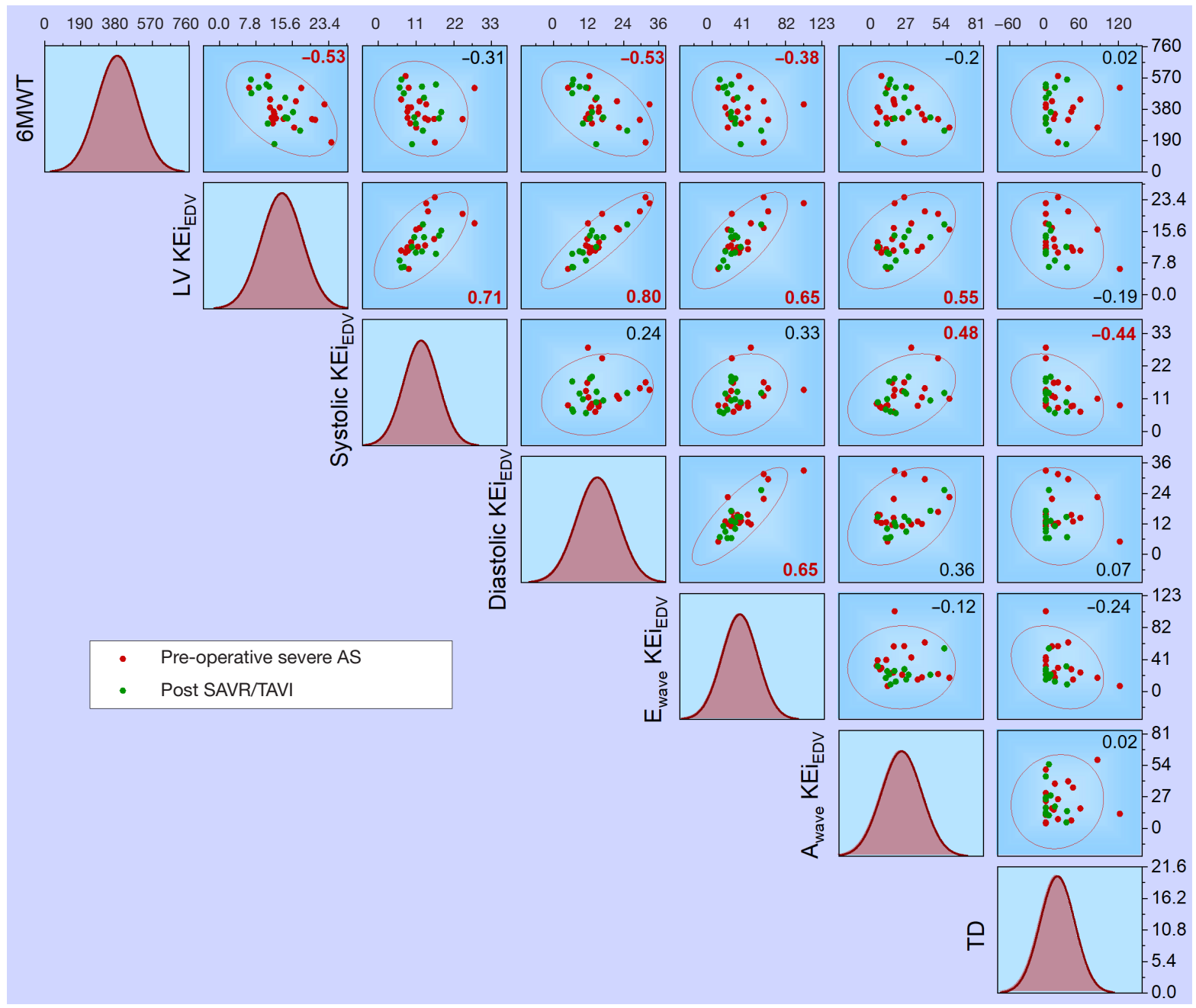

Figure 3 Scatter-matrix demonstrating data distribution for 6MWT and its association to LV blood flow KE in the whole study population both pre- and post-valvular intervention. $6 \mathrm{MWT}$, six-minute walk test; LV, left ventricle; KE, kinetic energy; TD, time delay.

physical endurance that could be a useful early parameter in the assessment of function, morbidity and perhaps prognosis in patients with AS. However, previous studies from our group have demonstrated that the average LV blood flow $\mathrm{KE}$ has a trend to reduce slightly with age, hence the association with $6 \mathrm{MWT}$ may become more relevant when a patient develops AS and requires longitudinal monitoring of progress. Future studies should evaluate clinical cut-offs which predict outcomes in AS.

It was worth noting that none of the non-invasive functional or haemodynamic parameters demonstrated association to NYHA functional class. While it is tempting to blame this on the subjectivity of NYHA functional class and to claim that it may have a limited role in precision medicine. However, we need to admit that NYHA class withstood the test of time since 1923 and remains broadly a reliable classification in making therapeutic decisions in cardiology.

\section{Early diastolic TD}

Normally, the blood flows rapidly into the LV cavity from the base to the apex of the heart. In this study, we measured the TD described before by our research group as a marker of LV compliance and diastolic function $(12,16)$. TD increases in patients who had an MI with preserved LVEF and also has a diagnostic value in patients with $L V$ thrombus. The significant reduction in TD reflects an improvement in restrictive LV filling after the valve intervention. This method is similar to the assessment 
Table 3 Correlation of both qualitative (NYHA functional class) and quantitative (the 6MWT) physical endurance to all haemodynamic and CMR imaging parameters

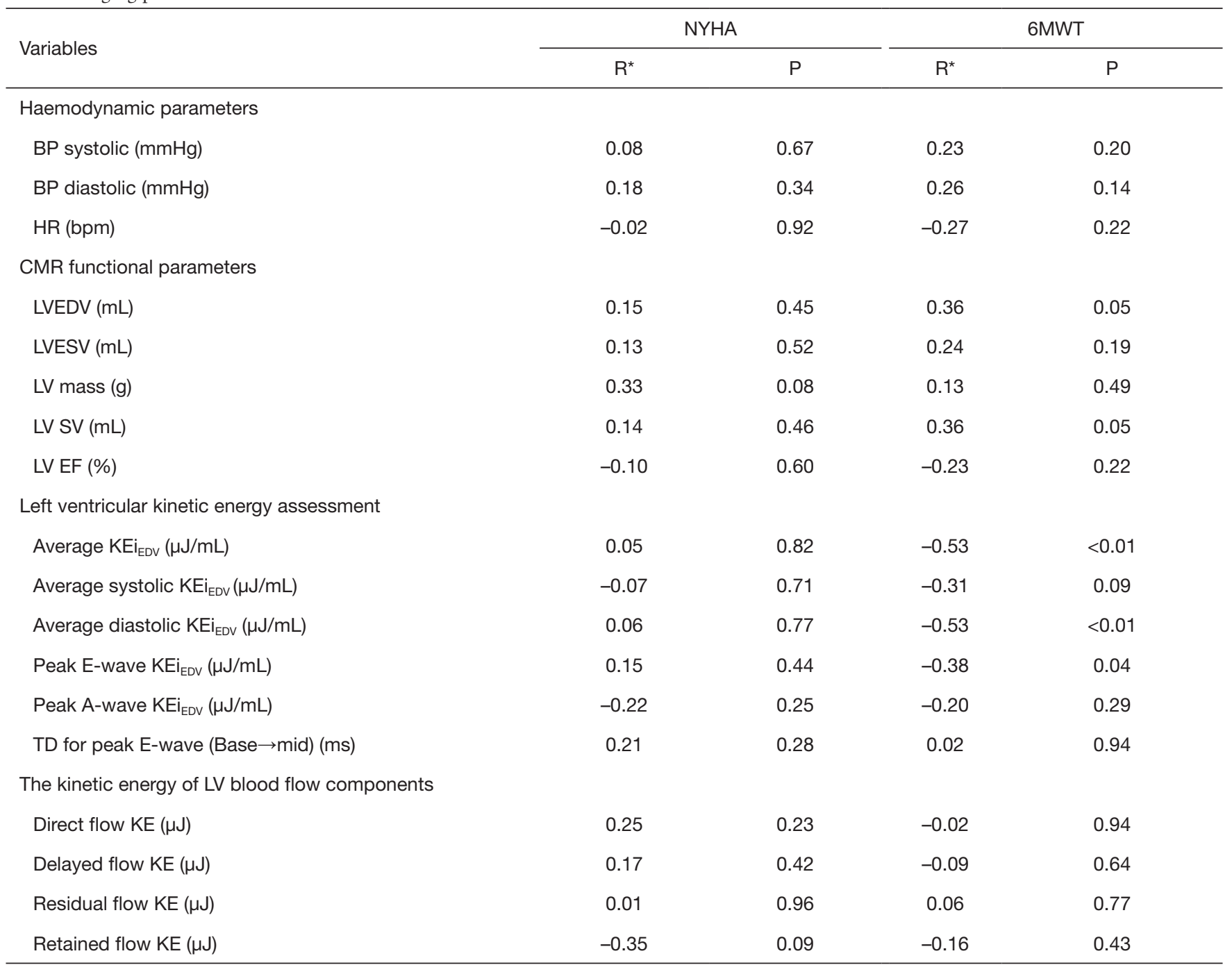

*, Spearman's rho correlation coefficient. BP, blood pressure; HR, heart rate; KE, kinetic energy; LV, left ventricular; LVEDV, left ventricular end-diastolic volume; LVESV, left ventricular end-systolic volume; SV, stroke volume; EF, ejection fraction; NYHA, New York Heart Association classification; TD, time delay; 6MWT, 6-minute walk test.

of the mitral valve flow propagation velocity $(\mathrm{Vp})$ by echocardiography, which is normally more than $50 \mathrm{~cm} / \mathrm{sec}(24)$. However, the TD here is derived automatically using 3D flow quantified data versus $\mathrm{VP}$ which is very susceptible to operator variability $(25,26)$.

\section{Predictors of positive $L V$ remodelling}

The only pre-operative CMR parameter which demonstrated good association to $\mathrm{LV}$ remodelling post valve intervention was average $\mathrm{LV}$ blood flow $\mathrm{KEi}_{\mathrm{EDV}}$ for the complete cardiac cycle. Both PG by echocardiography and CMR LVEF did not demonstrate any added value for prediction. In this small pilot study, peak $\mathrm{E}_{\text {wave }} \mathrm{KEi}_{\mathrm{EDV}}$ showed a trend towards association with $\mathrm{LV}$ remodelling. This is consistent with previous CMR study which demonstrated no added predictive value of routine PG and function assessment for LV remodelling in patients with AS $(21,22)$.

\section{Relation to earlier studies}

Although this study did not recruit healthy control, patients 
Table 4 Correlation of LV mass change pre-/post aortic valve replacement to imaging parameters

\begin{tabular}{|c|c|c|}
\hline Pre-operative CMR metrics & \multicolumn{2}{|c|}{ Absolute change in LV mass post-operatively } \\
\hline \multicolumn{3}{|l|}{ Routine assessment } \\
\hline LV EF (\%) & 0.36 & 0.25 \\
\hline Mean TTE PG (mmHg) & 0.11 & 0.73 \\
\hline Average $\mathrm{KEi}_{\mathrm{EDV}}$ & 0.67 & 0.02 \\
\hline Average systolic $\mathrm{KEi}_{\mathrm{EDV}}$ & 0.5 & 0.1 \\
\hline Average diastolic $\mathrm{KEi}_{\mathrm{EDV}}$ & 0.22 & 0.5 \\
\hline Peak E-wave KEi $\mathrm{EDV}_{\mathrm{E}}$ & 0.56 & 0.06 \\
\hline \multicolumn{3}{|c|}{ The kinetic energy of LV blood flow components } \\
\hline Direct flow KE & -0.26 & 0.43 \\
\hline Delayed flow KE & -0.44 & 0.18 \\
\hline Retained flow KE & -0.23 & 0.5 \\
\hline Residual flow KE & 0.07 & 0.83 \\
\hline
\end{tabular}

*, Spearman's rho correlation coefficient. KE, kinetic energy; LV, left ventricular; EF, ejection fraction; PG, pressure gradient; TD, time delay;

TTE, transthoracic echocardiogram.

with AS appear to have higher LV KE when compared to similar age group patients in previous studies $(12.0 \pm 3.4 \mathrm{vs}$. $8 \pm 1.3 \mu \mathrm{J} / \mathrm{mL}$ ) (23). This could be explained by the increased outflow tract velocity in this cohort. Also, the diastolic and peak E-wave KE were higher in this study when compared to Crandon et al.'s work, and may reflect higher degree of deterioration of LV compliance in AS patients than previously studied healthy controls.

\section{Clinical implications and future direction}

This study demonstrates the feasibility of three-dimensional quantification of blood flow in the LV cavity from the complete cardiac cycle in patients with AS. The results from this pilot work are hypothesis generating and the real clinical value of LV blood flow KE needs to be tested in a larger clinical cohort. From this study, it would seem that LV blood flow KE may offer novel imaging flowbased based biomarkers which reflect the true functional status of the patient quantified by the $6 \mathrm{MWT}$. The LV blood flow KE assessment may also have a prognostic role in understanding of $\mathrm{LV}$ remodelling post aortic valve intervention. However, as there is emerging evidence of multi-parametric CMR including tissue characterisation in AS assessment, the overall clinical role of LV blood flow $\mathrm{KE}$ assessment may only be complimentary. Nevertheless, this is likely to make CMR a more versatile tool for a comprehensive assessment of AS.

\section{Limitations and further works}

This study has some limitations. Because of small numbers of patients recruited to this study, findings are mainly hypothesis-generating. Future larger sample sizes with long-term studies are required to detect possible changes in intra-ventricular blood flow behaviour over a complete cardiac cycle, and potential differences according to the surgical approach. In addition, a direct age-matched comparison with healthy volunteers was not done in this study. Furthermore, assessment of the difference in LV $\mathrm{KE}$ profiles between the two different treatment options of the aortic valve replacement (TAVI and SAVR) would 


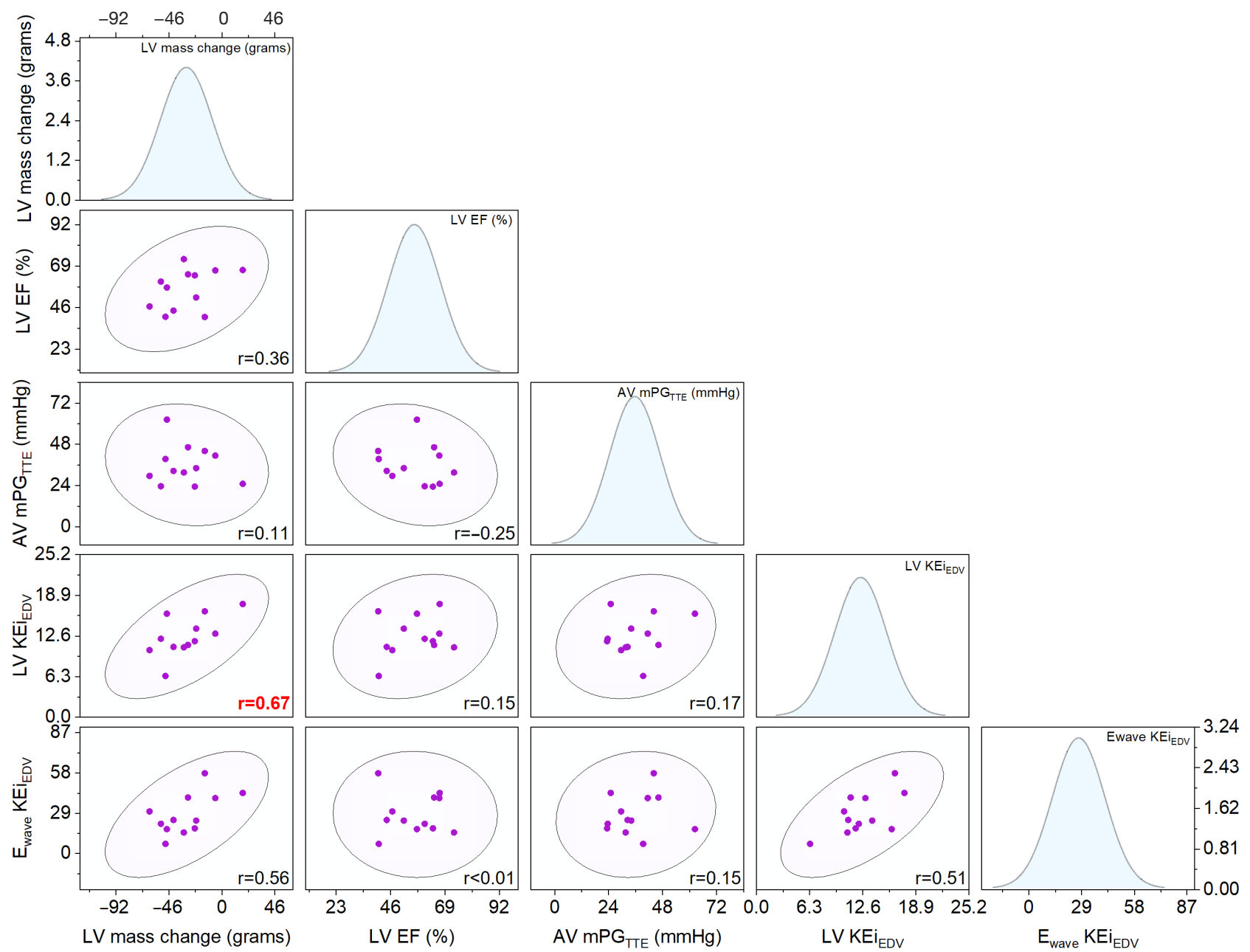

Figure 4 Scatter matrix demonstrating an association of LV remodelling post SAVR/TAVI is associated with pre-intervention LV blood flow KE only and not with LV EF or AV mPG. LV, left ventricle; KE, kinetic energy; SAVR, surgical aortic valve replacement; TAVI, transcatheter aortic valve implantation; EF, Ejection fraction; AV, aortic valve; $\mathrm{mPG}$, mean pressure gradient.

be interesting to study. Higher VENC settings in preoperative cases may have introduced noise in lower velocity profiles, which could influence our results.

\section{Conclusions}

$\mathrm{LV}$ blood flow $\mathrm{KE}$ is associated with $6 \mathrm{MWT}$ and $\mathrm{LV}$ remodelling in patients with AS. LV KE assessment demonstrates complimentary value to routine $\mathrm{LV}$ function and PG assessment in AS. Future prognostic and larger clinical studies are warranted to establish the cumulative role of routine LV blood flow KE assessment in patients with AS.

\section{Acknowledgments}

We thank the staff of the MRI unit at the University of Sheffield in facilitating all the CMR scans. In addition, we thank all the staff at the Cardiothoracic Department, Sheffield Teaching Hospitals NHS Foundation Trust for their support and help during this study.

Funding: This work was supported in part by EurValve (European Union funding) (Personalised Decision Support for Heart Valve Disease), Project Number: H2020 PHC30-2015, 689617. AR was supported by Clinical Research Career Development Fellowships from the Wellcome Trust (206632/Z/17/Z). AJS was supported by the Wellcome 
Trust (205188/Z/16/Z). PG was supported by the Academy of Sciences Starter Grant (SGL018/1100).

\section{Footnote}

Conflicts of Interest: All authors have completed the ICMJE uniform disclosure form (available at http://dx.doi. org/10.21037/qims-20-586). PG reports clinical advisor role to Medis Medical Imaging and Pie Medical Imaging. SH reports personal fees from AtriCure outside the submitted work. AAM reports personal fees from Novartis and from Astra Zeneca, both outside the scope of current study. The other authors have no conflicts of interest to declare.

Ethical Statement: The study was approved by the National Research Ethics Service (17/LO/0283), and sponsored by the Sheffield Teaching Hospitals (STH) NHS Foundation Trust. Written informed consent was obtained from all participants, in accordance with the Helsinki declaration.

Open Access Statement: This is an Open Access article distributed in accordance with the Creative Commons Attribution 4.0 International License (CC BY 4.0). See: https://creativecommons.org/licenses/by/4.0/.

\section{References}

1. Iung B, Baron G, Butchart EG, Delahaye F, GohlkeBärwolf C, Levang OW, Tornos P, Vanoverschelde JL, Vermeer F, Boersma E, Ravaud P, Vahanian A. A prospective survey of patients with valvular heart disease in Europe: The Euro Heart Survey on Valvular Heart Disease. Eur Heart J 2003;24:1231-43.

2. Nkomo VT, Gardin JM, Skelton TN, Gottdiener JS, Scott CG, Enriquez-Sarano M. Burden of valvular heart diseases: a population-based study. Lancet 2006;368:1005-11.

3. Baumgartner H, Falk V, Bax JJ, De Bonis M, Hamm C, Holm PJ, Iung B, Lancellotti P, Lansac E, Rodriguez Muñoz D, Rosenhek R, Sjögren J, Tornos Mas P, Vahanian A, Walther T, Wendler O, Windecker S, Zamorano JL; ESC Scientific Document Group. 2017 ESC/EACTS Guidelines for the management of valvular heart disease. Eur Heart J 2017;38:2739-91.

4. Saikrishnan N, Kumar G, Sawaya FJ, Lerakis S, Yoganathan AP. Accurate assessment of aortic stenosis: a review of diagnostic modalities and hemodynamics. Circulation 2014;129:244-53.

5. Dweck MR, Boon NA, Newby DE. Calcific aortic stenosis: a disease of the valve and the myocardium. J Am Coll Cardiol 2012;60:1854-63.

6. Bing R, Cavalcante JL, Everett RJ, Clavel MA, Newby DE, Dweck MR. Imaging and Impact of Myocardial Fibrosis in Aortic Stenosis. JACC Cardiovasc Imaging 2019;12:283-96.

7. Musa TA, Plein S, Greenwood JP. The role of cardiovascular magnetic resonance in the assessment of severe aortic stenosis and in post-procedural evaluation following transcatheter aortic valve implantation and surgical aortic valve replacement. Quant Imaging Med Surg 2016;6:259-73.

8. Garcia J, Barker AJ, Markl M. The Role of Imaging of Flow Patterns by 4D Flow MRI in Aortic Stenosis. JACC Cardiovasc Imaging 2019;12:252-66.

9. Chin CWL, Everett RJ, Kwiecinski J, Vesey AT, Yeung E, Esson G, Jenkins W, Koo M, Mirsadraee S, White AC, Japp AG, Prasad SK, Semple S, Newby DE, Dweck MR. Myocardial Fibrosis and Cardiac Decompensation in Aortic Stenosis. JACC Cardiovasc Imaging 2017;10:1320-33.

10. Rommel KP, von Roeder M, Latuscynski K, Oberueck C, Blazek S, Fengler K, Besler C, Sandri M, Lücke C, Gutberlet M, Linke A, Schuler G, Lurz P. Extracellular Volume Fraction for Characterization of Patients With Heart Failure and Preserved Ejection Fraction. J Am Coll Cardiol 2016;67:1815-25.

11. Crandon S, Elbaz MSM, Westenberg JJM, van der Geest RJ, Plein S, Garg P. Clinical applications of intra-cardiac four-dimensional flow cardiovascular magnetic resonance: A systematic review. Int J Cardiol 2017;249:486-93.

12. Garg P, Crandon S, Swoboda PP, Fent GJ, Foley JRJ, Chew PG, Brown LAE, Vijayan S, Hassell MECJ, Nijveldt R, Bissell M, Elbaz MSM, Al-Mohammad A, Westenberg JJM, Greenwood JP, van der Geest RJ, Plein S, Dall'Armellina E. Left ventricular blood flow kinetic energy after myocardial infarction - insights from 4D flow cardiovascular magnetic resonance. J Cardiovasc Magn Reson 2018;20:61.

13. Zhang JM, Tan RS, Zhang S, Geest RV, Garg P, Leong BR, Bryant J, Tangcharoen T, Zhao X, Tan JL, Westenberg JJ, Zhong L. Comparison of Image Acquisition Techniques in Four-Dimensional Flow Cardiovascular MR on 3 Tesla in Volunteers and Tetralogy of Fallot Patients. Annu Int Conf IEEE Eng Med Biol Soc 2018;2018:1115-8.

14. Garg P, Westenberg JJM, van den Boogaard PJ, Swoboda PP, Aziz R, Foley JRJ, Fent GJ, Tyl FGJ, Coratella L, ElBaz MSM, van der Geest RJ, Higgins DM, Greenwood 
JP, Plein S. Comparison of fast acquisition strategies in whole-heart four-dimensional flow cardiac MR: Twocenter, 1.5 Tesla, phantom and in vivo validation study. J Magn Reson Imaging 2018;47:272-81.

15. Archer GT, Elhawaz A, Barker N, Fidock B, Rothman A, van der Geest RJ, Hose R, Briffa N, Hall IR, Grech E, Bissell M, Al-Mohammad A, Treibel TA, Swift AJ, Wild JM, Garg P. Validation of four-dimensional flow cardiovascular magnetic resonance for aortic stenosis assessment. Sci Rep 2020;10:10569.

16. Garg P, van der Geest RJ, Swoboda PP, Crandon S, Fent GJ, Foley JRJ, Dobson LE, Al Musa T, Onciul S, Vijayan S, Chew PG, Brown LAE, Bissell M, Hassell MECJ, Nijveldt R, Elbaz MSM, Westenberg JJM, Dall'Armellina E, Greenwood JP, Plein S. Left ventricular thrombus formation in myocardial infarction is associated with altered left ventricular blood flow energetics. Eur Heart J Cardiovasc Imaging 2019;20:108-17.

17. Schulz-Menger J, Bluemke DA, Bremerich J, Flamm SD, Fogel MA, Friedrich MG, Kim RJ, von KnobelsdorffBrenkenhoff F, Kramer CM, Pennell DJ, Plein S, Nagel E. Standardized image interpretation and post processing in cardiovascular magnetic resonance: Society for Cardiovascular Magnetic Resonance (SCMR) board of trustees task force on standardized post processing. J Cardiovasc Magn Reson 2013;15:35.

18. van der Geest RJ, Garg P. Advanced Analysis Techniques for Intra-cardiac Flow Evaluation from 4D Flow MRI. Curr Radiol Rep 2016;4:38.

19. Brooks D, Solway S, Gibbons WJ. ATS statement on six-minute walk test. Am J Respir Crit Care Med 2003;167:1287.

20. Campbell I. Chi-squared and Fisher-Irwin tests of two-bytwo tables with small sample recommendations. Stat Med 2007;26:3661-75.

21. Dweck MR, Joshi S, Murigu T, Gulati A, Alpendurada F, Jabbour A, Maceira A, Roussin I, Northridge DB, Kilner PJ, Cook SA, Boon NA, Pepper J, Mohiaddin RH, Newby
DE, Pennell DJ, Prasad SK. Left ventricular remodeling and hypertrophy in patients with aortic stenosis: insights from cardiovascular magnetic resonance. J Cardiovasc Magn Reson 2012;14:50.

22. Raman B, Ariga R, Spartera M, Sivalokanathan S, Chan K, Dass S, Petersen SE, Daniels MJ, Francis J, Smillie R, Lewandowski AJ, Ohuma EO, Rodgers C, Kramer CM, Mahmod M, Watkins H, Neubauer S. Progression of myocardial fibrosis in hypertrophic cardiomyopathy: mechanisms and clinical implications. Eur Heart J Cardiovasc Imaging 2019;20:157-67.

23. Crandon S, Westenberg JJM, Swoboda PP, Fent GJ, Foley JRJ, Chew PG, Brown LAE, Saunderson C, Al-Mohammad A, Greenwood JP, van der Geest RJ, Dall'Armellina E, Plein S, Garg P. Impact of Age and Diastolic Function on Novel, 4D flow CMR Biomarkers of Left Ventricular Blood Flow Kinetic Energy. Sci Rep 2018;8:14436.

24. Hernandez-Suarez DF, Palm D, Lopez-Menendez F, Mesa Pabon M, Lopez-Candales A. Left Ventricular Velocity of Propagation: A Useful Non-Invasive Measurement When Assessing Hemodynamic Alterations in Pulmonary Arterial Hypertension. Cardiol Res 2017;8:44-51.

25. De Boeck BW, Oh JK, Vandervoort PM, Vierendeels JA, van der Aa RP, Cramer MJ. Colour M-mode velocity propagation: a glance at intra-ventricular pressure gradients and early diastolic ventricular performance. Eur J Heart Fail 2005;7:19-28.

26. Nagueh SF, Smiseth OA, Appleton CP, Byrd BF 3rd, Dokainish H, Edvardsen T, Flachskampf FA, Gillebert TC, Klein AL, Lancellotti P, Marino P, Oh JK, Alexandru Popescu B, Waggoner AD. Recommendations for the Evaluation of Left Ventricular Diastolic Function by Echocardiography: An Update from the American Society of Echocardiography and the European Association of Cardiovascular Imaging. Eur Heart J Cardiovasc Imaging 2016;17:1321-60.
Cite this article as: Elhawaz A, Archer CT, Zafar H, Fidock B, Barker N, Jones R, Rothman A, Hose R, Al-Mohammad A, Briffa N, Hunter S, Braidley P, Hall IR, Grech E, van der Geest RJ, Gunn JP, Swift AJ, Wild JM, Garg P. Left ventricular blood flow kinetic energy is associated with the six-minute walk test and left ventricular remodelling post valvular intervention in aortic stenosis. Quant Imaging Med Surg 2021;11(4):1470-1482. doi: 10.21037/qims-20-586 


\section{Supplementary}

Table S1 Comparison of patients in atrial fibrillation with patients in sinus rhythm.

\begin{tabular}{|c|c|c|c|}
\hline Variable & Sinus rhythm $(n=12)$, median [IQR] & Atrial fibrillation $(n=6)$, median [IQR] & $\mathrm{P}$ \\
\hline LVEDV (mL) & $128[55]$ & $115[70]$ & 0.34 \\
\hline LVESV (mL) & $46[39]$ & $47[43]$ & 0.75 \\
\hline LV SV (mL) & $85[17]$ & $68[22]$ & 0.03 \\
\hline LV mass (g) & $140[60]$ & $122[90]$ & 0.44 \\
\hline NYHA & $2[0]$ & $3[1]$ & 0.26 \\
\hline 6MWT & 339 [113] & $378[115]$ & 0.96 \\
\hline Average $\mathrm{KEi}_{\mathrm{EDV}}$ & $13[6]$ & $12[11]$ & 0.82 \\
\hline Peak E-wave $\mathrm{KEi}_{\text {EDV }}$ & 23 [24] & $36[28]$ & 0.08 \\
\hline Peak A-wave* KEi $\mathrm{E}_{\text {EDV }}$ & 27 [23] & - & - \\
\hline
\end{tabular}

*, peak $\mathrm{A}$-wave $\mathrm{KEi}_{\mathrm{EDV}}$ cannot be compared as in $\mathrm{AF}$ it is not recorded.

Table S2 Linear regression results between absolute LV mass regression and preoperative $\mathrm{LV}$ blood flow $\mathrm{KE}$.

\begin{tabular}{lc}
\hline Variables & Value \\
\hline Least squares regression & 12 \\
Sample size & 0.37 \\
Coefficient of determination $\mathrm{R}^{2}$ & 18.8 \\
Residual standard deviation & $\mathrm{y}=-86.7155+4.4940 \mathrm{x}$ \\
Regression equation & Coefficient \\
Parameter & -86.7155 \\
Intercept & 4.494 \\
Slope & \\
Analysis of variance & $\mathrm{DF}$ \\
Source & 1 \\
Regression & 10 \\
Residual & 5.9933 \\
F-ratio & $\mathrm{P}=0.03$ \\
Significance level & \\
\hline
\end{tabular}

